\section{No association between the serotonin transporter promoter region (5-HTTLPR) and the dopamine D3 receptor (Ball D3DR) polymorphisms and heroin addiction}

SIR - Family and twin studies in man support a significant role of heredity in contributing to substance abuse and various genes have been examined for association with both alcohol and opioid abuse. Although early reports found no association between the dopamine D3 receptor (D3DR) Ball (gly $\rightarrow$ ser) restriction site polymorphism and cocaine addiction ${ }^{1}$ or alcoholism, ${ }^{2}$ homozygosity in this gene (gly/gly \& ser/ser vs gly/ser) has been recently linked to substance abuse in two circumscribed groups: schizophrenia ${ }^{3}$ and heroin addicts ${ }^{4}$ showing high sensation-seeking scores on a self-report personality questionnaire.

An additional candidate polymorphism for a role in addiction is a 44-base pair region in the serotonin transporter promoter region (5-HTTLPR) whose absence results in reduced transporter expression and which is associated in some ${ }^{5}$ but not all investigations ${ }^{6}$ with anxiety or Harm Avoidance. Our observation that a representative group of Israel $i$ heroin addicts exhibit high TPQ Harm Avoidance scores, ${ }^{7}$ persuaded us to examine both the D3DR and 5-HTTLPR polymorphisms in this group of male, non-Ashkenazi heroin addicts we have previously genotyped for the dopamine D4 exon III repeat polymorphism and who display an excess of the long repeat alleles of this gene. ${ }^{7,8}$

Table 1 shows the genotype and al lel e distribution of the dopamine D3 receptor polymorphism in 193 heroin addicts compared to an ethnically matched group of
134 control subjects. No significant overall difference in allele (Pearson $\chi^{2}=0.049$, d.f. $=1, P>0.1$ or genotype (Pearson $\chi^{2}=3.15$, d.f. $=2, \mathrm{P}>0.1$ ) frequency between addicts and controls was observed.

Since excess homozygosity was reported at the Ball D3DR site for sensation seeking compared to non-sensation seeking addicts we also examined the distribution of the gly/gly \& ser/ser vs gly/ser genotypes. Opposite to expectations, a trend for excess homozygosity was observed in the control group (Fisher's exact test, $P=0.091$ ). Since additional genetic information is available for these subjects, we also parsed genotypes by examining the association between addiction and the D3DR polymorphism in those subjects lacking the long seven allele of the dopamine D4 receptor exon III repeat polymorphism. An association between heroin addiction and the D3DR Ball polymorphism genotype was observed in this subgroup of subjects (Pearson $\chi^{2}=5.97$, d.f. $=2, P=0.051$ ). The control group showed excess homozygosity, gly/gly \& ser/ser vs gly/ser (Fisher's exact test, $P=0.021$ ). A representative, albeit small, group of these heroin addicts has been previously inventoried for TPQ personality questionnaires ${ }^{7}$ allowing us to test for an association between Novelty Seeking scores and D3DR homozygosity within the addict group. Analysis of these 32 heroin addicts (Figure 1) fails to reveal a trend for increased D3DR Ball homozygosity in high Novelty Seekers (Fisher's exact test, $\mathrm{P}>0.1$; grouping subjects by TPQ Novel ty Seeking scores $<>18$ ).

As shown in Table 2, no significant difference in allele (Pearson $\chi^{2}=0.068$, d.f. $=1, P>0.1$ ) or genotype distribution (Pearson $\chi^{2}=2.24$, d.f. $=2, \mathrm{P}>0.1$ ) was observed between 217 control individuals and 186 heroin addicts when the serotonin promoter region (5HTTLPR) polymorphism was inventoried in these subjects. Neither was any difference observed (Pearson $\chi^{2}$ $=1.09$, d.f. $=1, \mathrm{P}>0.1$ ) if the genotypes of the trans-

Table 1 Allele and genotype frequency for dopamine D3 receptor polymorphism

\begin{tabular}{|c|c|c|c|c|c|c|c|}
\hline & \multicolumn{2}{|c|}{ Allele frequency } & \multicolumn{3}{|c|}{ Genotype frequency } & \multicolumn{2}{|c|}{ Homozygosity } \\
\hline & Glycine & Serine & Gly/Gly & Gly/Ser & Ser/Ser & $\begin{array}{c}\text { Gly/Gly \& } \\
\text { Ser/Ser }\end{array}$ & Gly/Ser \\
\hline \multicolumn{8}{|c|}{ I. Heroin addicts vs controls } \\
\hline Control & $171(64 \%)$ & $97(36 \%)$ & $59(44 \%)$ & $53(40 \%)$ & $22(16 \%)$ & $81(60 \%)$ & $53(40 \%)$ \\
\hline Addicts & $243(63 \%)$ & $143(37 \%)$ & $74(35 \%)$ & $95(49 \%)$ & $24(12 \%)$ & $98(51 \%)$ & $95(49 \%)$ \\
\hline \multicolumn{8}{|c|}{ II. Subjects lacking the 7 repeat allele of the D4DR polymorphism } \\
\hline Control & $92(83 \%)$ & $19(17 \%)$ & $50(45 \%)$ & $42(38 \%)$ & $19(17 \%)$ & $69(62 \%)$ & $42(39 \%)$ \\
\hline Addicts & $123(89 \%)$ & $15(11 \%)$ & $50(36 \%)$ & $73(53 \%)$ & $15(11 \%)$ & $65(47 \%)$ & $73(53 \%)$ \\
\hline
\end{tabular}

The dopamine D3 Ball receptor polymorphism was assessed as previously described by this laboratory. ${ }^{9}$ 
Table 2 Allele and genotype frequency for serotonin transporter promoter region polymorphism (5-HTTLPR)

\begin{tabular}{|c|c|c|c|c|c|c|c|}
\hline & \multicolumn{2}{|c|}{ Allele frequency } & \multicolumn{3}{|c|}{ Genotype frequency } & \multicolumn{2}{|c|}{ Short vs Long } \\
\hline & Short & Long & $S / S$ & $S / L$ & $\mathrm{~L} / \mathrm{L}$ & $\mathrm{L} / \mathrm{L}$ & $L / S \& S / S$ \\
\hline \multicolumn{8}{|c|}{ Heroin addicts vs controls } \\
\hline Control & $220(51 \%)$ & $214(49 \%)$ & $50(23 \%)$ & $114(53 \%)$ & $53(24 \%)$ & $53(24 \%)$ & $164(76 \%)$ \\
\hline Addicts & $192(52 \%)$ & $180(48 \%)$ & $48(26 \%)$ & $84(45 \%)$ & $54(29 \%)$ & $54(29 \%)$ & $132(71 \%)$ \\
\hline
\end{tabular}

The 5-HTTLPR polymorphism was assessed as previously described by this laboratory. ${ }^{6}$

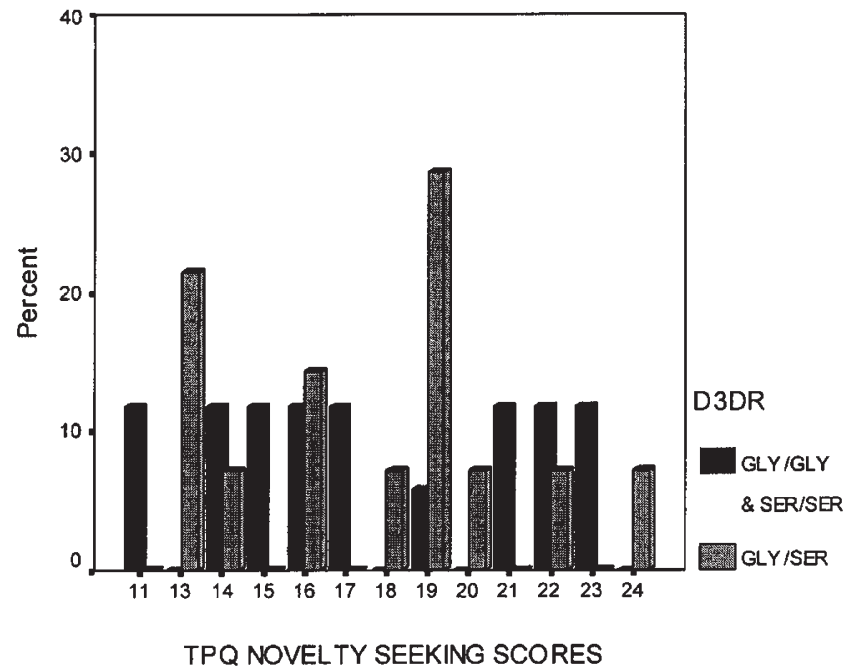

Figure 1 TPQ Novelty Seeking scores grouped by homozygosity at the DRD3 Ball restriction site. TPQ Novelty Seeking scores and D3DR Ball genotypes were inventoried for 32 previously studied heroin addicts. ${ }^{7}$

porter polymorphism were collapsed (short/short \& short/long vs long/long) as originally suggested by Lesch. ${ }^{5}$ We also failed to observe an association between 5-HTTLPR and Harm Avoidance (one way ANOVA: $F=0.238, P=0.789$, d.f. $=2,39$ ) in a small group of 42 heroin addicts for whom we had TPQ scores. This group had previously been studied and showed significantly higher Harm Avoidance scores than a matched control group. ${ }^{7}$

Neither the Ball D3DR of 5-HTTLPR polymorphisms appear to contribute directly to opioid abuse. A role for these two genes in modifying the clinical characteristics of drug addiction is perhaps suggested by several recent studies ${ }^{3,4}$ but the number of subjects examined and the case control design employed advise caution in their interpretation. Family-based association studies such as the haplotype relative risk design as well as larger case control samples and additional inventorying of more common polymorphisms across ethnic and population divisions, will likely resolve the reasons for our apparent failure to validate early findings.

\section{Acknowledgements}

This research was partially supported by the Israeli Anti-Drug Authority (Grant Administrator is Dr Rachel Bar-Hamburger).

M Kotler ${ }^{1}$, H Cohen ${ }^{1}$, I Kremer', H Mel $^{3}$, R Horowit ${ }^{3}$, N Ohel ${ }^{3}$, I Gritsenko ${ }^{4}$, L Nemanov ${ }^{4}, \mathrm{M} \mathrm{Kat}^{4}$ and RP Ebstein $^{4}$

${ }^{1}$ Beersheva Mental Health Center, Faculty of Health Sciences, Ben-Gurion University of the Negev, PO Box 4600, Beersheva, Israel; '2Department of Psychiatry, Emek Hospital, Israel; Kfar Malkishua Association; ${ }^{4}$ Research Laboratory, S Herzog Memorial Hospital, Israel, PO Box 35300, Jerusalem 91351, Israel

Correspondence should be addressed to RP Ebstein. E-mail: ebstein@ netmedia.net.il

\footnotetext{
1 Freimer M et al. Addiction Biol 1996; 1: 281-287.

2 Higuchi $S$ et al. Am J Med Genet 1996; 67: 412-414.

3 Krebs MO et al. Mol Psychiatry 1998; 3: 337-341.

4 Duaux E et al. Mol Psychiatry 1998; 3: 333-336.

5 Lesch KP et al. Science 1996; 274: 1527-1531.

6 Ebstein RP et al. Mol Psychiatry 1997; 2: 224-226.

$7 \mathrm{Mel} \mathrm{H}$ et al. Addiction Biol 1998; 3: 473-481.

8 Kotler M et al. Mol Psychiatry 1997; 2: 251-254.

9 Ebstein RP et al. Hum Hered 1997; 47: 6-16.
}

\section{SNPs and polygenic disorders: a less gloomy view}

SIR - The recent article in Science entitled A closer look at SNPs suggests difficulties, ${ }^{1}$ reported presentations at a Swedish meeting that cast a gloomy view on the use of SNPs for identifying disease associations. The presentations pointed out that for the lipoprotein lipase gene there had been almost as much recombination as mutation, SNPs were unable to identify the role of the $\beta$-globin mutation in sickle cell disease, and more than $90 \%$ of the new disease genes reported in the American Journal of Human Genetics during the past 1.5 years had more than 10 disease-producing mutations. This difficulty is analogous to that of diagnosing single gene disorders by PCR testing for mutations. For example, a sampling of some of the 